\title{
Characteristics of the Lipopolysaccharide from Pasteurella piscicida*
}

\author{
Fulvio Salati, ${ }^{1,2}$ Shigeki KawaI, ${ }^{3}$ and Riichi KusUda ${ }^{1}$ \\ ${ }^{1}$ Fish Disease Laboratory, Faculty of Agriculture, Kochi University, \\ Nankoku, Kochi 783, Japan \\ ${ }^{2}$ Present address: Laboratoire d'Ichtyopathologie, Institut National de la \\ Recherche Agronomique, 78350 Jouy-en-Josas, France \\ ${ }^{3}$ Biomedical Research Lab., Earth Chemical Co. Ltd. 3218, Sakoshi Ako, \\ Hyogo 678-01, Japan
}

(Received January 10, 1989)

\begin{abstract}
Chemical analysis and toxic ty assay of Pasteurella piscicida lipopolysaccharide (LPS) preparations used for immunization of yellowtail (Seriola quinqueradiata) were performed. LPS fractions were obtained by the phenol-water (P-LPS) or phenol-chloroform-petroleum ether (PCP-LPS) methods followed by purification with Cetavlon or ultracentrifugation, respectively. P-LPS was composed of $0.87 \%$ protein, $24.0 \%$ sugar and $36.0 \%$ fatty acid. Whereas PCP-LPS of $0.34 \%$ protein, $18.0 \%$ sugar and $34.2 \%$ fatty acid. The monosaccharide of P-LPS and PCP-LPS was respectively: $30.6 \%$ and $16.5 \%$ hexose; $3.8 \%$ and $2.1 \%$ heptose; $2.2 \%$ and $3.6 \%$ pentose; $2.2 \%$ and $3.2 \%$ 6-deoxyhexose; $3.2 \%$ and 2.6\% 2-keto-3-deoxyoctonate (KDO); and $2.8 \%$ and $2.4 \%$ hexosamine. The fatty acids were analyzed by gas-liquid chromatography (GLC) as their methyl esters. Their identities were confirmed by mass spectrometry. Those analyses showed that the principal constituents were: lauric acid, 3-hydroxy lauric acid, myristic acid and palmitic acid. The acute toxicity assay using mice injected i.p. showed that the P-LPS preparation was more toxic than PCP-LPS. The Limulus amoebocyte assay did not show differences between the two preparations.
\end{abstract}

Pseudotuberculosis is one of the most important diseases of cultured yellowtail (Seriola quinqueradiata) in Japan. Pasteurella piscicida is a fish pathogen which causes a systemic disease characterized by grayish white lesions particularly at spleen and kidney (SIMIDU and Egusa, 1972; KusUda and YAMAOKA, 1972). Attempts have been made to prepare vaccines against pseudotuberculosis (FUKUDA and KUSUDA, 1981; KusUdA and HAMAGUCHI, 1987, 1988; KUSUDA et al., 1988), and a preparation of $P$. piscicida lipopolysaccharide (LPS) was shown to give good protection to an experimental infection (FUKUdA and KUSUdA, 1985).

Depending on the disease, discussed is the possibility of application of bacterial LPSs as useful vaccines. Moreover, bacterial LPSs play

* The outline of this report was presented at the International Colloquium Microbiology in Poecilotherms, Paris, France, July, 1989. an important role as antigen which could induce both humoral and cellular immune response of fish. Production of specific antibody to LPS was demonstrated in many fishes and also in yellowtail immunized with a $P$. piscicida LPS preparation (FUKUDA and KUSUDA, 1985). Activation of phagocytosis after immunization with bacterial LPS was demonstrated in other fish as eel (SAlati and Kusuda, 1986a; Salati et al., 1987). And only recently activation of phagocytic cells was showed after immersion of yellowtail in a $P$. piscicida LPS (KAWAHARA and Kusuda, 1988). In the present study, $P$. piscicida LPS was analyzed for chemical composition, lethal toxicity and Limulus amoebocyte-gelating activity. 


\section{Materials and Methods}

\section{Microorganism}

Pasteurella piscicida strain U-3 was used, which was originally isolated from the kidney of a diseased yellowtail from Tosa-Shi, Kochi Prefecture, Japan, in June 1979.

\section{Preparation of LPSs and hydrolysates}

Strain U-3 was cultured in Todd-Hewitt broth (Difco) containing $2 \% \mathrm{NaCl}$ at $25^{\circ} \mathrm{C}$ for 48 hours, then centrifuged. The pellet was washed by centrifugation with distilled water. LPS was extracted from the pellet by the Westphal's phenol-water method (WESTPHAL and JANN, 1965), followed by purification with cetyltrimethylammonium bromide (Cetavlon) to afford P-LPS. Otherwise, it was extracted by the Galanos phenol-chloroform-petroleum ether method (GALANOS et al., 1969), followed by ultracentrifugation at $100,000 \times g$ for 4 hours to afford PCP-LPS. Both LPSs were lyophilized and stored at $5^{\circ} \mathrm{C}$ until used. For degradation of the P-LPS, mild acid hydrolysis was carried out and lipid A was separated as a sediment, with the polysaccharide (PS) fraction in the supernatant as previously described (SALATI et al., 1984). Alkali-PS was obtained by hydrolysis of P-LPS with $\mathrm{NaOH} 0.25 \mathrm{~N}\left(50^{\circ} \mathrm{C}, 5\right.$ hours), followed by acidification with acetic acid and extraction with chloroform. These PS preparations were also lyophilized and stored at $5^{\circ} \mathrm{C}$ until used. Salmonella minnesota Re 595 LPS was obtained from List Biological Laboratories, INC. (Campbell, California, USA).

\section{Analytical methods}

Protein was determined by the method of LOWRY et al. (1951). Sugar was determined using the phenol-sulfuric acid method (DuBoIs et al., 1956). For determination of 2-keto-3deoxyoctonate (KDO), the periodate-thiobarbituric acid method was used (DRöGE et al., 1970). Pentose was determined with the cysteine-sulfuric acid method (Dische, 1949); hexose with the cysteine-sulfuric acid method (DISCHE et al., 1949); heptose with a modification of the Osborn method (OsBorn, 1963) and 6-deoxyhexose with the cysteine sulfuric acid method
(Dische and Shettles, 1948). Hexosamine was determined by the Elson-Morgan method (BLIx, 1948). The quantity of fatty acids was determined enzymically using a Non-Esterified Fatty Acid (NEFA)-C Test (Wako Pure Chemical Ind., Osaka, Japan). The components of the fatty acids were identified using gas chromatography. Alkali hydrolysis of the LPSs was made as previously described (SALATI and Kusuda, 1985). Gas-liquid chromatography/ mass spectrometry (GLC-MS) of the fatty acid methyl esters was performed on a Shimadzu GCMS-QP 1000 instrument, using a 1\% SE-30 column, source temperature at $250^{\circ} \mathrm{C}$, ionizing voltage at $70 \mathrm{eV}$ and helium as carrier gas.

\section{Lethality test}

Male 5-week-old ICR mice were injected intraperitoneally with $10 \mathrm{mg}$ of each preparation per kg. Mortality was recorded after 7 days and $\mathrm{LD}_{50}$ was determined by the method of Litchfield and Wilcoxon (1949).

\section{Limulus assay}

Limulus Amoebocyte Lysate (LAL) assay was performed using a Limulus HS-Single Test (Wako Pure Chemical Ind., Osaka, Japan). The preparations examined were: P-LPS, PCPLPS, and PSs of $P$. piscicida strain U-3 and LPS of $S$. minnesota strain $\operatorname{Re} 595$ as positive control.

\section{Results}

The chemical analysis of the two LPSs from $P$. piscicida strain U-3 is summarized in Table 1. P-LPS and PCP-LPS contained respectively: 0.87 and $0.34 \%$ protein, 24.0 and $18.0 \%$ sugar, 36.0 and $34.2 \%$ fatty acid, 3.2 and $2.6 \% \mathrm{KDO}$, 2.2 and $3.6 \%$ pentose, 30.6 and $16.5 \%$ hexose, 3.8 and $2.1 \%$ heptose, 2.2 and $3.2 \%$ 6-deoxyhexose, 2.8 and $2.4 \%$ hexosamine.

As much as one third of total weight was accounted for fatty acids (Table 1). In gas chromatography, the fatty acid methyl esters from P-LPS elicited 6 peaks (Fig. 1). Peaks 1,4 , and 6 were identified as 12:0,14:0, and $16: 0$, respectively. Peaks 2 , and 3 were respectively identified as $12: 1$, and a 3-hydroxy fatty acid (3-OH 12:0). Peak 5 was judged to 
Table 1. Chemical analysis of two types of lipopolysaccharide obtained from Pasteurella piscicida strain U-3

\begin{tabular}{lcc}
\hline \hline Constituents & $\begin{array}{c}\text { P-LPS } \\
(\%)\end{array}$ & $\begin{array}{c}\text { PCP-LPS } \\
(\%)\end{array}$ \\
\hline Protein & 0.87 & 0.34 \\
Sugar & 24.0 & 18.0 \\
Fatty acid & 36.0 & 34.2 \\
Monosaccharide: & & \\
KDO & 3.2 & 2.6 \\
Pentose & 2.2 & 3.6 \\
Hexose & 30.6 & 16.5 \\
Heptose & 3.8 & 2.2 \\
6-Deoxyhexose & 2.2 & 3.2 \\
Hexosamine & 2.8 & 2.4 \\
\hline
\end{tabular}

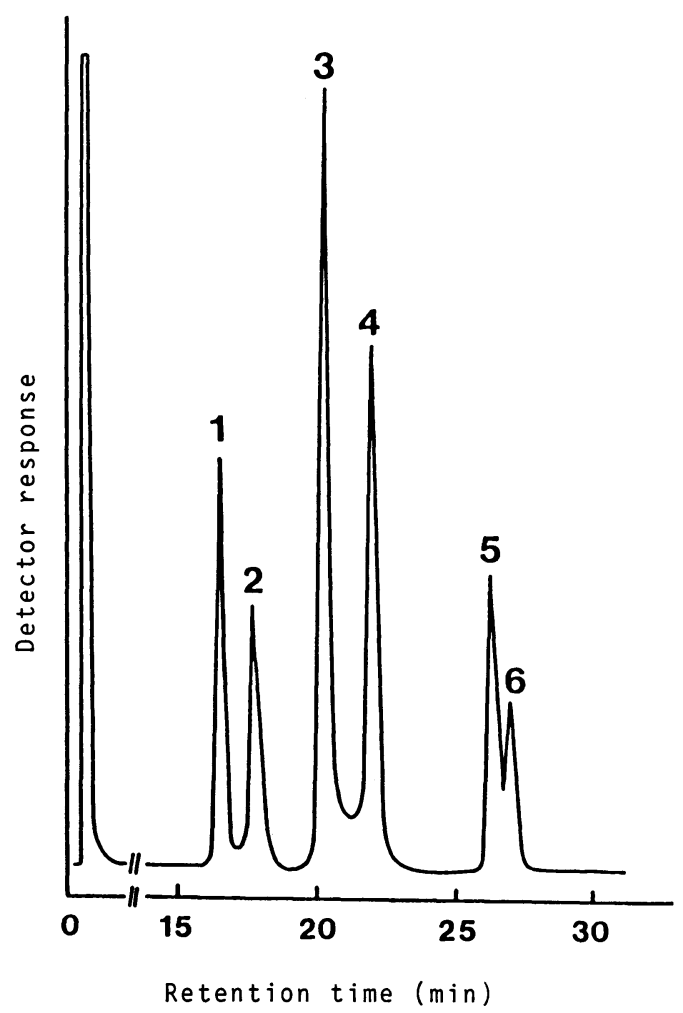

Fig. 1. Gas-chromatogram of fatty acids from $\mathrm{Pa}$ steurella piscicida P-LPS.

be an unsaturated fatty acid of $16^{\circ} \mathrm{C}$ (mass spectra not showed).

The acute toxicity of the LPSs and hydrolysates preparations is shown in Table 2. PLPS was more toxic than PCP-LPS. PS preparations from P-LPS were found to be less
Table 2. Acute toxicity in mice injected i.p. with P-LPS, PCP-LPS, PS, and alkali PS obtained from Pasteurella piscicida U-3

\begin{tabular}{cc}
\hline \hline Preparations & $\mathrm{LD}_{50}(\mathrm{mg} / \mathrm{kg})$ \\
\hline P-LPS & $25.6-34.1(30.5) *$ \\
PS & $>100$ \\
alkali PS & $>100$ \\
PCP-LPS & $74.1-89.1(81.6)$ \\
\hline
\end{tabular}

* Figures in parentheses indicate a mean of values from a group of five mice.

Table 3. Limulus Amoebocyte Lysate (LAL) activity of P-LPS, PCP-LPS, PS, and alkali PS from Pasteurella piscicida U-3 and LPS from Salmonella minnesota $\operatorname{Re} 595$

\begin{tabular}{lc}
\hline \hline Preparations & LAL activity $(\mu \mathrm{g} / \mathrm{m} l$ saline $)$ \\
\hline U-3 P-LPS & $10^{-4}$ \\
U-3 PS & $10^{-1}$ \\
U-3 alkali PS & $10^{-2}$ \\
U-3 PCP-LPS & $10^{-4}$ \\
Re 595 LPS & $10^{-5}$ \\
\hline
\end{tabular}

toxic. Results of the Limulus amoebocyte gelation assay are shown in Table 3. S. minnesota LPS, which was used as a reference, was positive with a dose of $10^{-5} \mu \mathrm{g} / \mathrm{m} l$; while both $P$. piscicida LPS preparations were less active: one tenth of the $S$. minnesota LPS activity. The PS preparations were the less active.

\section{Discussion}

The damages caused by $P$. piscicida infection of cultured yellowtail in Japan stress the necessity of protective vaccine. One of the substances which seems to activate the phagocytic cells (Kawahara and Kusuda, 1988) and which showed protection to experimental infection (FUKUdA and KusUdA, 1985) was LPS extracted from $P$. piscicida cells. In this study, the composition and some characteristics of LPS preparations from $P$. piscicida strain U-3 were examined.

The monosaccharide constituents of LPSs from $P$. piscicida U-3 were similar to those from other Pasteurella, confirming a bacteriological relationship with Enterobacteriaceae (LüDERITZ et al. 1968). It was indicated that Pasteurella LPS is the major antigen responsible 
for typing based on gel diffusion precipitin tests (MANNing, 1984). In the sugar composition of LPSs, $P$. piscicida showed similarities to several strains of $P$. multocida, $P$. pestis, $P$. septica and $P$. pseudotuberculosis groups (LüDERITZ et al., 1968). However, the content of KDO of $P$. piscicida LPSs was more than that of $P$. multocida LPS, while the protein content was less (MANNIKG, 1984). The difference in hexose contents between P-LPS and PCP-LPS of $P$. piscicida were explained by the different methods employed for extraction (GALANOS et al., 1977).

The principal components of $P$. piscicida lipid A were, as for many other bacteria, lauric acid, myristic acid and palmitic acid. Also 3-hydroxy lauric acid was found in the fatty acids of $P$. piscicida, as for Pseudomonas aeruginosa, P. rubescens, Bordetella bronchiseptica and Vibrio cholerae (GAlANOS et al., 1977). While, different from $E$. coli, S. minnesota, $P$. aeruginosa, $P$. putrefaciens and Edwardsiella tar$d a$, 3-hydroxy myristic acid was not detected (TAYlor et al., 1966; KASAI and Nowotny, 1967; Fensom and Gray, 1969; Wilkinson and Caudwell, 1980; Salati and Kusuda, 1985); and different from $V$.ordalii, arachidic acid was not found in $P$. piscicida lipid A (SAlAti and KusudA, 1986b). The quantity of fatty acids present in P-LPS and PCP-LPS of P. piscicida was very high $(36.0 \%$ and $34.2 \%$, respectively). This quantity was more than that found using the same analysis method for E. tarda $(8.3 \%)$ (SAlati and Kusuda, 1985) and for $V$. ordalii and $V$. anguillarum (1.4\% and $11.3 \%$ ) (SALATI and Kusuda, 1986b). However, for $P$. pestis LPS, a quantity of $50 \%$ of fatty acids has been reported (LüDERITZ et al., 1968). This high quantity of fatty acids explains and justifies the practical difficulties to obtain a good $P$. piscicida LPS preparation for subministration.

The results of the acute toxicity test on mice demonstrated that P-LPS was most toxic, while, the PS preparations did not show remarkable toxicity. This is obvious that the preparations without 3-hydroxy fatty acids were inactive in in vivo tests (ТАNAMOTO et al., 1984). The results of the Limulus amoebocyte gelation assay did not show differences between LPS preparations. Both LPSs were, however, less active than $S$. minnesota LPS used as positive control. Even if routinely used as a general toxicological tests, the validity of the Limulus Amoebocyte Lysate (LAL) assay for fish will be discussed, since $P$. piscicida LPS was not toxic in yellowtail (FUKUDA and Kusuda, 1985).

Finally, from the point of view of vaccinal preparation, the results of this study supported by the above mentioned induction of cell mediated immunity and the absence of toxicity for yellowtail of the LPS from $P$. piscicida, indicate the possibility of practical applications, provided that difficulties on expenses for production are overcome.

\section{References}

BLIx, G. (1948): The determination of hexosamines according to Elson and Morgan. Acta Chem. Scand., 2, 467-473.

Dische, Z. (1949): Spectrophotometric method for determination of free pentose and pentose in nucleotides. J. Biol. Chem., 181, 379-392.

Dischez, Z. and L. B. Shettles (1948): A specific color reaction of methylpentoses and a spectrophotometer micromethod for their determination. J. Biol. Chem., 175, 595-603.

Dische, Z., L. B. Shettles and M. OsNos (1949): New specific color reactions of hexoses and spectrophotometric micromethods for their determination. Archives Biochem. Biophys., 22, 169-184.

DRÖGE, W., V. LehMANN, O. LüDERITZ and $O$. WestPhAL (1970): Structural investigations on the 2-keto-3-deoxyoctonate region of lipopolysaccharides. Eur. J. Biochem., 14, 175-184.

Dubois, M., K. A. Gilles, J. K. Hamilton, P. A. Rebers and F. SMITH (1956): Colorimetric method for determination of Sugars and related substances. Anal. Chem., 28, 350-356.

Fensom, A. H. and G. W. Gray (1969): The chemical composition of the lipopolysaccharide of $P_{s e-}$ udomonas aeruginosa. Biochem. J., 114, 185-196.

FuKUDA, Y. and R. KUSUdA (1981): Efficacy of vaccination for pseudotuberculosis in cultured yellowtail by various routes of administration. Nippon Suisan Gakkaishi, 47, 147-150. (in Japanese).

FUKUDA, Y. and R. KusUdA (1985): Vaccination of yellowtail against pseudotuberculosis. Fish Pathol., 20, 421-425.

Galanos, C., O. Lüderitz, E. T. Rietschel and O. WeSTPHAL (1977): Newer aspects of the chemistry and biology of bacterial lipopolysaccharides with 
special reference to their A component. By T. W. GoodwIN "Biochemistry of lipids II". Vol. 14. University Park Press, Baltimore, 239-335.

Galanos, C., O. Lüderitz and $O$. Westphal (1969): A new method for the extraction of $R$ lipopolysaccharides. Eur. J. Biochem., 9, 245-249.

KaSAI, N. and A. Nowotny (1967): Endotoxic glycolipid from heptoseless mutant of Salmonella minnesota. J. Bacteriol., 94, 1824-1836.

Kawahara, E. and R. Kusuda (1988): Location of Pasteurella piscicida antigens in tissues of yellowtail Seriola quinqueradiata vaccined by immersion. Nippon Suisan Gakkaishi, 54, 1101-1105.

Kusuda, R. and M. Hamaguchi (1987): A comparative study on efficacy of immersion and a combination of immersion and oral vaccination methods against pseudotuberculosis on yellowtail. Nippon Suisan Gakkaishi, 53, 1005-1008. (in Japanese).

Kusuda, R. and M. Hamaguchi (1988): The efficacy of attenuated live bacterin of Pasteurella piscicida against pseudotuberculosis in yellowtail. Bull. Eur. Ass. Fish Pathol., 8, 50-52.

Kusuda, R., M. Ninomiya, M. Hamaguchi and A. MuraOKA (1988): The efficacy of ribosomal vaccine prepared from Pasteurella piscicida against pseudotuberculosis in cultured yellowtail. Fish Pathol., 23, 191-196. (in Japanese).

KusudA, R. and M. YamaOKA (1972): Etiological studies on bacterial pseudotuberculosis in cultured yellowtail with Pasteurella piscicida as the causative agent. I. On the morphological and biochemical properties. Nippon Suisan Gakkaishi, 38, 1325-1332. (in Japanese).

LitChField, J. T. and F. Wilcoxon (1949): A simplified method of evaluating dose-effect experiments. J. Pharmac. exp. Ther., 96, 99-103.

Lowry, O. H., N. J. Rosebrough, A. L. FARr and R. J. Randall (1951): Protein measurement with the Folin Phenol Reagent. J. Biol. Chem., 193, 265-275.

Lüderitz, O., K. JANN and R. WheAT (1968): Somatic and capsular antigens of Gram-negative bacteria. By Florkin, M. and Stotz, E. H. "Comprehensive biochemistry", Vol. 26, 105-228.

MANNING, P. J. (1984): Naturally occurring pasteurellosis in laboratory rabbits: chemical and serological studies of whole cells and lipopolysaccha- rides of Pasteurella multocida. Infect. Immun., 44, 502-507.

Osborn, M. J. (1963): Studies on the Gram-negative cell wall I. Evidence for the role of 2-keto-3deoxyoctonate in the lipopolysaccharide of Salmonella typhimurium. Proc. N.S.A., U.S.A., 50, 499506.

Salati, F., K. Kawai and R. Kusuda (1984): Immune response of eel to Edwardsiella tarda lipopolysaccharide. Fish Pathol., 19, 187-192.

Salati, F. and R. Kusuda (1985): Gas-cromatografia-spettrometria di massa del lipide A dell' $E d$ wardsiella tarda. Arch. Vet. It., 37, 43-52.

Salati, F. and R. Kusuda (1986a): Immune response of eel to Edwardsiella tarda lipid. Fish Pathol., 21, 201-205.

Salati, F. and R. Kusuda (1986b): Chemical composition of the lipopolysaccharides from Vibrio anguillarum and Vibrio ordalii. Fish Pathol., 21, 193199.

Salati, F., Y. Ikeda and R. Kusuda (1987): Effect of Edwardsiella tarda lipopolysaccharide immunization on phagocytosis in the eel. Nippon Suisan Gakkaishi, 53, 201-204.

Simidu, U. and S. EguSA (1972): A re-examination of the fish-pathogenic bacterium that had been reported as a Pasteurella piscicida. Nippon Suisan Gakkaishi, 38, 803-812.

Tanamoto, K., U. Zähringer, G. R. McKenzie, C. Galanos, E. T. RietsChel, O. LüDERItZ, S. Kusuмото and T. SHibA (1984): Biological activities of synthetic lipid A analogs: pyrogenicity, lethal toxicity, anticomplement activity and induction of gelation of Limulus amoebocyte lysate. Infect. Immun., 44, 421-426.

TAYLOR, A., K. W. KNOX and E. WORK (1966): Chemical and biological properties of an extracellular lipolysaccharide from $E$. coli grown under lysine-limiting conditions. Biochem. J., 99, 53-61.

WestPhal, O. and K. JANN (1965): Bacterial lipopolysaccharides. Extraction with phenol-water and further applications of the procedure. By R. L. Whistler, J. N. BeMiller and M. L. Wolfrom: "Methods in carbohydrate chemistry", Vol. 5, Academic Press, New York, 83-91.

Wilkinson, S. G. and P. F. Caudwell (1980): Lipid composition and chemotaxonomy of Pseudomonas putrefaciens. J. Gen. Microbiol., 118, 239-241. 